\title{
Research on Reservation and Circulation Mode of Ancient Books in University Libraries in China
}

\author{
Mao Mao \\ Nanyang Institute of Technology, Nanyang Henan, 473000, China
}

Keywords: University Library, Reservation of Ancient Books, Circulation Mode

\begin{abstract}
University libraries symbolize the culture and history of universities. The reservation of ancient books is important to university libraries. Ancient books have accumulated the historic culture and gathered human intelligence, and are the cultural heritage, which should be respected and protected. University libraries are open to a large number of persons, and the number of borrowers of ancient books is also large. If no proper protection measures are taken and no good library management is performed, the books are likely to flow out, or be destroyed, which will become a great loss to universities. In view of this, discussions and analysis on the method of management and protection of ancient books in university libraries have been made in this article. Actually, to preserve ancient books is to protect the valuable historical and cultural heritage.
\end{abstract}

\section{Introduction}

There is a special department in the library service system, i.e. the department of ancient books. The daily work of this department includes protection and management of ancient books. The completeness and value of ancient books vary with their length of existence. The staff in university libraries, students and teachers in universities all desire to figure out a good way to sort and protect the ancient books better, so as to ensure the permanent and safe circulation. Furthermore, the ancient literature materials are special, and there is much room for tap the social effect of ancient books, which is another emphasis in the management of ancient books of university libraries.

\section{Development and Historical Positioning of Thread-bound Ancient Books}

From ancient times, China has accumulated profound culture contents and rich cultural heritage. The intelligent ancient Chinese people invented printing and papermaking technology, which created the basic conditions for making books, and materials subsequently. Thanks to the printing and papermaking technology, the classic literatures could be generated and come down. As the technology of book publishing became increasingly developed, more and more books became available, whether for reading or reservation. This had greatly promoted the spread and popularization of books, having laid a foundation for cultural communication. Presently, most of the books written and coming down from the Song and Yuan Dynasties are housed at university libraries, the thread-bound books from the period from the late Qing Dynasty until 1949 can be circulated, and many ancient books have been included into cultural relics and put under protection. There are many reprints of ancient books in paperback form, and few thread-bound books. Apart from some thread-bound ancient books provided to teachers for consultation, most are restricted for circulation and borrowing. Although the restriction of circulation and borrowing makes for the integrity and safety of the thread-bound ancient books, the right of readers of direct reading has been greatly restricted, and students' chance of touching ancient books has been greatly reduced. In the viewpoint of students, the thread-bound ancient books are valuable cultural relics so that they can only enjoy the books from a distance. Thus, they hardly can acquire knowledge from these books, and their horizon and view cannot be effectively broadened, which should be taken seriously. Universities always take library as the documentation center, and the important place where students acquire knowledge. The collection of ancient books and materials is a long process. In order to reach a large scale, resources should be fully integrated, and both teachers and students should made their efforts to 
recognize the historical role of reservation of ancient books[1]. As the valuable results of arduous struggles of ancient Chinese people, ancient books are the evidence of the evolutionary process of the human civilization, and provide a foundation to people for exploring culture and nature, which are the derivation of human intelligence. Ancient books provide knowledge in various fields, including politics, economics, philosophy, geography, science and technology, military science, etc., which are inexhaustible treasury of knowledge for the human beings. More specifically, the ancient books cover palaeography, local chronicles, biography, chronicle, travel notes, collection of poems, literature, catalogue, etc.; can be divided into reference books with material taken from various sources and series compiled with books for users with a certain purpose by the form of book formation. The carrier of ancient books has been changing throughout the long evolutionary process. Basically, the ancient books were written to record information and experience. Due to old-fashioned cognition and limited knowledge of writers, deviation or error of conception were unavoidable. Thus, the librarians should constantly update their concepts, improve their knowledge, and optimize their historical attainment, and continuously innovate the method of books management, to manage books orderly and well, to offer convenience to readers. Nowadays, the work related to ancient books has gradually turned from a closed state to an open state, and from the mode of manual collection and sorting to the mode of information processing, becoming a comprehensive collection and management service integrating consultation, research, opening and utilization. This is the main difference between modern library work and reservation of ancient books in the past[2].

\section{Reservation History of Thread-bound Ancient Books and Related Knowledge}

By the grade and the mode of management and circulation of thread-bound books, different reservation methods should be selected and different cognitions are generated. Books, the important cultural heritage of China, also are the source of sustainable development and progress of society. Since the establishment of the library system, the rulers in every dynasties all had set up a special management department of collected books to take charge of the circulation and management of books. For example, library collection and private collection were the main modes of books circulation and management in the Qing Dynasty. The publishing or circulation of books were complicated at that time. However, the number of private library, academy and bookstore took an increasing tendency. At that time, book collection was prevailing. Especially, the scale, group and area of book collection were unprecedented in the place where poets and literary men gathered. For example, Huang Zongxi, Weng Fanggang, etc., learned scholars at that time, were famous book collectors, who had greatly promoted cultural communication. Ancient people were strict in dividing and compiling the catalogue and the content of books, and the department of books collection were more strict in the links of collation, examination, and correction, which should be referred to in the management of ancient books by modern libraries. In order to facilitate the reservation, circulation, and borrowing of ancient books, university libraries can organize the staff to compile the catalogue, key words, and library card, etc. In this way, readers can quickly search the ancient books they desire by the catalogue, key words or abstract[3]. The quantity and quality of ancient books are an important symbol of library' s culture and history, and regarded as the support of academic strength of universities. Presently, the books in state-owned libraries are provided not only for reading and cultural communication, but also for serving society, to contribute the public cultural undertakings. Furthermore, the ancient books have survived thousands of years, and it is a tough work to preserve these books which have experienced a long history. Therefore, these ancient books should be protected as cultural relics, and the whole nation should strive to protect these valuable cultural heritages. The sorting of ancient books is a demanding job in knowledge and technicality. The staff of library should be proficient in bibliology, textual criticism, bibliography, literature, and historiography, and computer technology that can facilitate the collection, sorting, development and utilization of ancient books as well, so as to contribute to cultural exchange and communication. 


\section{Innovation of Management and Protection Technology of Thread-bound Ancient Books in University Libraries}

People will get different feelings and knowledge from different types of book. The main functions of books are reading and digesting. Different from ancient bronze objects, porcelain, inscriptions on bones or tortoise shells of the Shang Dynasty, and other historical relics of such kind, ancient books are of no practical significance unless be sorted and read. Therefore, there are special stacks for reserving the valuable ancient books set up in university libraries. Most universities cannot do well in the management and protection of ancient books due to limited conditions and facilities as the private book collectors in the past did, who collected complete volumes, specially prepared book cabinet, and highly value these books. Presently, the national library, provincial libraries and university libraries own a large quantity of ancient books. To preserve the ancient books well, these libraries specially provide a stack room, and store some ancient books in metal cabinet or wooden cabinet. Generally, the ancient books are arranged by the content, which can raise the efficiency of book search and looking up, to facilitate the circulation of ancient books, and satisfy the needs of readers as far as possible. Ancient books also are referred to as historical documents. The paper of ancient books, the carrier, is soft, light, low acid, undeformable, easy to transport and handle, etc., but liable to be dampened or go mouldy. Furthermore, the paper would yellow and becomes less tough as time lapses[4]. Controlling the temperature and humidity of the stack room to prevent books from being dampened, going mouldy, or being damaged due to water, fire, insects is an important task of university libraries. Hence, university libraries should specially assign persons to inspect and take care of the library, and establish a standardized management system. In order to avoid damage to the valuable thread-bound ancient books, more efforts should be made in management, such as tightening up the conditions for borrowing book, enhancing related education of teachers and students. As far as teachers and students are concerned, they should form a good habit of taking care of and protecting the books, and abide by the social morality, lightly turning pages, and not folding, smearing, painting or tearing up any book. Any one who violates the foregoing provisions should be subject to punishment. The top concern of libraries is to improve the reading right and the right of information sharing of the thread-bound ancient books of teachers and students, protect the ancient books in library well, and give full play to the ancient books. Due to different historical conditions of different regions and universities, the quantity, quality and content of books collection also are different. Notwithstanding, strict rules and regulations in respect of the bidirectional utilization, sharing and communication of the ancient books should be established and complied with according to particular situations of university libraries, to explore the information in the books. Besides, consideration also should be taken to the system and method, which is vital to the sustainable development and construction of a library. Since the establishment of the P.R.C., the construction of library has been flourishing, and taken on a new took. Meanwhile, the personal quality of librarians also is increasingly improved. With the scientific and technological progress and social development, library management gains more and more recognition and support form the academic circle. In order to put the use ratio of ancient books under control, the pace of technological development should be kept with. Many university libraries have introduced information technology and information systems, with which it is convenient to look up the catalogue of ancient books and related materials. Building a database integrating the catalogue, abstract and content of books with advanced scientific methods, and establishing an open ancient book resource information supporting system for sharing and complementation on line are of great significance.

In the age when the scientific and technical information is constantly developing and evolving, it is a long way to build an overall and scientific ancient book database, which become more and more urgent. Many universities are aware of it. Then, university libraries set to construct libraries orderly and actively. The number of comprehensive universities with a long history is large, but the number of universities emphasized the preservation and management of thread-bound ancient books early is small. More worse, many ancient books were dispersed due to transformation of some universities. In despite of this, tends of thousands of thread-bound ancient books have been collected with the concerted effort and exploration of educators and under the support of related polices, laws and 
regulations of the country, and even some universities have a book collection up to 20 volumes. However, some rare books are neither put under special protection and preservation nor taken care of by specially-assigned persons. There are many rare books, unique books in the library in a university in the northwest region of China, including the Book of the Southern Qi Dynasty, the Story of An Lushan, the Variorum of the Book of Changes, the Variorum of the Collection of Poems of Wang Youcheng in the Tang Dyansty, the History Run-through Authentication of the Song and Yuan Dynasties, etc. These books, covering literature, history, religion, etc., are of irreplaceable reference significance to academic research[5]. Presently, many universities start organizing persons to uniformly register, summarize and sort the thread-bound ancient books housed in the reference rooms by the specialty of literature, history, astronomy and so on, to build a database and facilitate the management of materials. At the same time, light disks of ancient books also are made, which is an effective means to permanently preserve the ancient books, avoid damage to the books due to borrowing and circulation, and facilitate the reservation, search, spread and regeneration.

\section{Constantly Improving the Service Level and Individual Quality of the Staff of University Libraries}

Librarians play an important role in the orderly and standardized daily operation of libraries. In order to provide more convenient and attentive services, and set an example in the management and protection of ancient books, they should improve their individual quality, getting familiar with the basic features of thread-bound ancient books, and continuously improving their efficiency of management. The readers in universities include undergraduate, postgraduate and professor, of whom book usage varies with the educational level, purpose of reading, and research field. Thus, librarians should not only provide attentive service and patient guidance, but also provide assistance to more people in reading ancient books based on the particular needs, so that the readers can get something and support the cultural communication and academic research, as an old saying goes, "Two heads are always better than one." Dull as ancient book management is, librarians also can enjoy the work, and realize the value of cultural disseminator and coordinator as long as their enthusiasm is aroused, they are happy to make discovery and innovation, and actively blend themselves into the environment. In addition to raising the service awareness and the basic professional competence, librarians also should master information technology to facilitate the procedure of book borrowing and reading, including the using of cold light source scanner, the processing of images and texts in books with special camera, and the editing and producing of the processed images and texts for reproduction of books, because university libraries tend to build a library collection database with modern technology so as to handle a large quantity of books. In the process of building a library collection database, the title, classification, writer, the year of publication, print time, and the number of volume of books also should be verified one by one, and the books should be classified by the content and field for search, to form a multi-media database. With this database, a reader can search the book he desires by inputting the key words of the book into the system, which can greatly increase the efficiency. Hence, librarians should have a good command of computer operation, or actively accept computer training, to facilitate their work.

\section{Conclusion}

The reservation of ancient books is not only the evidence of cultural history and the academic identity of universities, but also the common cultural wealth of all mankind; marks the profound historic and cultural connotation and the course of spiritual civilization development of China; is an important carrier of cultural communication. Protecting and preserving the ancient books is an important mission of every person. In this article, the method of management and circulation of ancient books in university libraries have been introduced, and the importance of keeping the management and circulation of ancient books advancing with the times has been pointed out. Conforming to the trend of development is favorable to inheriting and preserving the ancient books perfectly, and promoting the construction of the public cultural undertakings. 


\section{References}

[1] FAN Chunli. Discussions on Strategy of Resource Construction of Ancient Books of Local University Libraries-Library of Weinan Vocational and Technical College. Western China Quality Education, 2015(9): 17-17.

[2] CAI Yunfeng. Discussions on Strategy of Resource Construction of Ancient Books of Local University Libraries-Library of Shaoguan University. Journal of Shaoguan University, 2015(1): 178-180.

[3] CHU Li, NING Yong. On the Value from the Aspects of "Historical Relics, Academic Information and Academic Representative" of Sealing Style of Ancient Books-Sealing Style of Ancient Books in the Library of Jilin Academy of Social Sciences. Journal of Tonghua Normal University, 2014(5): 71-75.

[4] GE Huaidong. Enlightenment of Digital Book Reservation in Taiwan to the Digitalization Project of Ancient Books in Mainland China. Journal of the Library Science Society of Sichuan,2014(2):95-97.

[5] YANG Xiaohua. Suggestions on General Survey and Protection of Ancient Books-Library of the Northwest Normal University. Silk Road, 2013(20): 64-65. 